\title{
The Development of Multidisciplinary Core Competencies: The First Step in the Professionalization of Disaster Medicine and Public Health Preparedness on a Global Scale
}

\author{
Frederick M. Burkle Jr, MD, MPH, DTM
}

$\mathrm{D}$ uring this past decade, the field of disaster medicine has gained increasing attention from practitioners and policy makers, in no small part due to the growing body of evidence-based peer reviewed publications containing quality research and policy advances that have better defined the widening scope of this emerging discipline. In the actual prevention, preparedness, response, and recovery from disasters, disaster medicine itself is only one of many disciplines that define what is operatively best seen through the collective lens of "disaster management" of crisis events and their many causes—and solutions.

It can be argued that the art and science of disaster management is a multidisciplinary effort, a reminder that the solution for and actual success and failure of health outcomes in both domestic and global disasters rarely depend on health resources alone. While most professions have accepted this multidisciplinary mandate, the education, training, research, and the field-level operational functioning and its machinery fall short of or outright fail to meet expectations. In great part this is a "front-end" problem, failing first to define accurately the multiple competencies that define these mandates.

Medical practitioners will assert that their specialty training is sufficient to respond to a major disaster. However, the great majority of responders to the 2010 earthquake in Haiti were 30 years old or younger, and participating in their very first major crisis event. Moreover, to many of them, the experience confirmed the disparity between the requirements of disasters that occur in a relatively peaceful and cooperative environment limited by time and geography and those that occur in the midst of a widespread, pervasive, and often complex public health emergency. ${ }^{1}$

The Haiti disaster, as well as the 2004 south Asian tsunami, exposed "unacceptable practices in the delivery of international emergency medical assistance," raising "serious questions about the clinical competencies and practices of some of the foreign medical teams." ${ }^{2}$ The subsequent Pan American Health Organization/World Health Organization (PAHO/ WHO) meeting in Cuba in December 2010 recognized the lack of overall "coordination, quality control and oversight" and called for the immediate "need for international standards for health

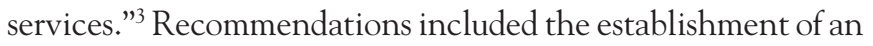

international register of provider organizations including academic, governmental (including military and civil-military teams), and nongovernmental bodies to promote universal accountability, inclusiveness, and transparency. ${ }^{2}$ This effort complements global initiatives already in motion to professionalize humanitarian assistance through competency-based education and training of the aid workforce community who staff the provider organizations. ${ }^{4,5}$

While these two pieces of this process are crucial, inevitably there must be an overarching global authority for crises and accountability similar to that mandated by the International Health Regulations Treaty of $2005 .{ }^{6}$ This treaty remains the primary international legal treaty specifically focused on infectious disease control and ensures ongoing global cooperation for surveillance and coordinated WHO action when a threat emerges. International agreements for global health engagement are commonplace in today's world, and, for the United States, the Obama Administration has clearly stated an "intention to reinvigorate multilateral relationships and international partnerships on health and development." I assert that development of the requisite competency-based education and training will eventually energize and pressure the disaster and humanitarian community and its stakeholder organizations to collectively lobby for an umbrella global authority - but only when the multidisciplinary discipline can show operational evidence of its own professional core competency base.

To ensure that the base composition of policy, public health, and practice exist to support such initiatives, core competencies first must be in place and functioning. This task is not easy, but if it is not accomplished, then any claims of preparedness remain empty ones. The framework for accountable aid to global crises begins in the competency-based education and training of workforce practitioners and decision-makers at home, where many future responders "cut their teeth" on performance in domestic disasters. This necessary first step often humbles practitioners into recognizing and acknowledging that the demands beyond their profession are equally critical to their performance in the field as a team member. Whereas many major disasters differ greatly, the common thread that ultimately surfaces and defines severity and recovery stems from averting the development of a public health emergency-one that risks 
becoming pervasive and catastrophic. ${ }^{1}$ Prevention and preparedness may mitigate direct consequences such as deaths and injuries, but once crises abate or become chronic, as in the massive Christchurch, New Zealand, earthquakes and aftershocks that lasted more than 12 months, the goal becomes the control of preventable, excess mortality and morbidity arising from a public health collapse.

Whereas sole attention is too often concentrated on the emergency-phase response- and we certainly have fostered a generation of "emergency-phase addicts" - the true measure of one who can legitimately claim to be a disaster expert requires an equal proportion of knowledge and competencies in field public health awareness and skill sets. Any "authentic" emergencyphase responder constantly seeks evidence of the early decline in health indices that uncover the more foreboding public health emergency. In the memorable crises we study, more people over time suffer from destroyed public health infrastructure and failed social protections, whether they result from war, a major earthquake, tsunami, or a nuclear plant explosion. For disaster medicine and public health preparedness, this knowledge and experience expands into a set of "core competencies" beyond any "specific" competencies based on professional degrees previously earned by, for example, health care workers, epidemiologists, public health professionals, logisticians, human rights experts, and human resource or security personnel. What every national or foreign medical team member will have in common is those core competencies that allow everyone to function adequately as a team with other teams, and to support organizations found in the uniquely culturally challenging environments of a major crisis.

In this issue of Disaster Medicine and Public Health Preparedness, Walsh and colleagues publish their study on core competencies for disaster medicine and public health. ${ }^{8}$ Using a methodological approach consistent with a young, evolving discipline, the authors have gained national consensus from an inclusive and broad body of more than 80 private and public professions and stakeholders (medicine, public health, nursing, emergency management, academe) that are appropriate and essential for this specific multidisciplinary effort.

The authors initiated four Web-based surveys from a diverse group of national stakeholders, refining content at each incremental level. Ultimately, their efforts led to a final review of key leadership in public health and private agencies and organizations to seek final validation of the core competencies. The process was open and transparent and used a weighted survey methodology with reasonable cutoff points. The resulting 11 core competencies defined are broad in scope and reflect the phases of the disaster cycle (preparedness, mitigation, response, and recovery). Readers should note that with any multidisciplinary discipline there will be a necessary in-depth process of vetting that requires multiple input, review, and evaluation at every level. In general, the competencies in this study are reasonably consistent with the consensus of evidence in the published literature.

One of the more powerful contributions is the illustrative pyramid model, which demonstrates increased specialization and integration as an aspiring disaster expert moves up from the base. A key piece of this model highlights areas for potential certification. While this article is an excellent effort, it represents one small piece of the overall system that needs to come together for a true multidisciplinary profession to be established. The system must also include ownership from certifying authorities (eg, professional societies, academic boards) and, inevitably, an integrated multidisciplinary system (medical and public health being just one) that will draw from these professionals operationally under one global authority. ${ }^{6}$

On the national scene, this study supports the forthcoming Implementation Plan for The National Health Security Strategy of the United States. ${ }^{9}$ This document plans, within its four-year framework, the development and maintenance of the workforce needed for national health security. It includes representatives from both the Office of the Assistant Secretary for Preparedness and Response (ASPR) and the Department of Defense (DoD), working together with partners to prioritize and develop examples of competency-based knowledge and skills that could be included in job descriptions for public health, health care, behavioral health, and other national health security personnel and interprofessional health and supporting teams. The ASPR and DoD will lead the Federal Education and Training Interagency Group (FETIG), which has responsibility for coordinating the implementation of applicable laws and executive directives related to core competencies and education and training standards, as directed by the Homeland Security Presidential Directive. The FETIG also will provide advice to the National Center for Disaster Medicine and Public Health (NCDMPH), which is housed in the Uniformed Services University of the Health Sciences. The NCDMPH will lead and coordinate national efforts to develop and propagate core curricula, education, training, and research in all-hazards disaster health. ${ }^{9}$

Enhancing Learning and Research for Humanitarian Assistance (ELRHA) is the first collaborative network dedicated to supporting partnerships between higher education institutions and humanitarian organizations and partners worldwide. ELRHA aims to effect a global humanitarian community in which humanitarian actors actively collaborate with higher education institutes to develop competency-based highly professional responders, share expertise, and conduct research that noticeably reduces risk. It also intends to facilitate humanitarian organizations in finding the expertise they need to investigate and act on humanitarian challenges. ${ }^{5}$ The process already has active regional hubs in North America, the United Kingdom, Europe, and East Africa. Both core and health-specific competencies have been launched as well as a nascent Association of Academic Training Centers in Humanitarian Health, which serves the 12 existing academic training centers in North America that have offered either Master's degrees 
and/or certificates of training during the past 2 to 17 years in competency-based training at entry, middle, and higher levels.

Many noteworthy competency-based efforts to improve professionalism have emerged, and several are being field tested; a few are referenced here. ${ }^{10-15}$ ELHRA has found that usually professional disciplines start small, with a dedicated group of professionals determined to defend the values and competencies of their profession. The ELRHA process has tapped categories of knowledge in security and safety issues, education, protection, statistical analysis and demographics, monitoring and evaluation methods, needs assessment, water supply and sanitation, food, nutritional and food security, public health, logistics, accounting, refugee and human rights law, and international humanitarian law. ${ }^{5}$

In 1906, Sir William Osler wrote: "Medicine is the only worldwide profession, following everywhere the same methods, actuated by the same ambitions, and pursuing the same ends. The homogeneity, its most characteristic feature, is not shared by the law, and not by the Church, certainly not in the same degree." ${ }^{16}$ This rather prophetic statement is applicable today to any effort to expand these and other competencies globally. In time, national efforts in every region of the world will find common ground, especially in realizing universal acceptance for competencies in health practices. However, even then, one should expect regional and national barriers that negatively risk access and availability of health services. Ultimately, these barriers will result in inequities in outcomes to the most vulnerable populations that may not be fully revealed until a major disaster occurs. These hurdles, based on long-term cultural, religious, gender, and political practices, have unfortunately changed little or become more problematic since observed by Osler more than a century ago. However, it should be encouraging that health practitioners in the developing world are among the most ardent supporters of the professionalization process based on common core competencies.

According to Walsh et al, their study "outlines a set of clear, concise, and precise training standards that may be used to ensure workforce competency in disaster medicine and public health" as a first step in "delineating expected competency levels." "The authors have accomplished and, most importantly, presented standards for a vetting process crucial to the development of multidisciplinary core competencies. Although demanding, challenging, and time-consuming, this process gives credit to their work and serves as an example of what can be accomplished on a global scale.

Author Affiliation: Dr Burkle, a Woodrow Wilson International Scholar, is Senior Fellow, Harvard Humanitarian Initiative, and Visiting Scientist, Harvard University School of Public Health, Cambridge, Massachusetts.

Correspondence: Frederick M. Burkle Jr, MD, MPH, DTM, Harvard Humanitarian Initiative, Harvard University, 14 Story St, Second Floor, Cambridge, MA02138 (e-mail: fburkle@hsph.harvard.edu).

Received for publication January 30, 2012; accepted February 6, 2012.

\section{REFERENCES}

1. Burkle FM Jr, Greenough PG. Impact of public health emergencies on modern disaster taxonomy, planning, and response. Disaster Med Public Health Prep. 2008;2(3):192-199.

2. Inter-Agency Standing Committee Global Health Cluster. Concept Paper: Foreign Medical Teams; May 17, 2011. http://www.who.int/hac/global _health_cluster/about/policy_strategy/fmt_concept_paper_16may11 .pdf. Accessed January 26, 2012.

3. Pan American Health Organization World Health Organization. Proceedings of the WHO/PAHO Technical Consultation on International Foreign Medical Teams (FMTs) Post Sudden Onset Disasters (SODs), December 7-9, 2010. Havana, Cuba. http://new.paho.org. Accessed January 26, 2012.

4. Walker P, Hein K, Russ C, Bertleff G, Caspersz D. A blueprint for professionalizing humanitarian assistance. Health Aff (Millwood). 2010;29(12): 2223-2230.

5. Walker P, Russ C Professionalising the Humanitarian Sector: A Scoping Study. Cardiff, United Kingdom: Enhanced Learning and Research for Humanitarian Assistance; April 2010. http://www.elrha.org/uploads/Professionalising _the_humanitarian_sector.pdf. Accessed January 26, 2010.

6. Burkle FM Jr, Redmond AD, McArdle DF. An authority for crisis coordination and accountability. Lancet. 2011;(October):17. Published online ahead of print.

7. Kates J, Katz R. U.S. Global Health Policy. U.S Participation in International Health Treaties, Commitments, Partnerships, and Other Agreements. Menlo Park, California: The Henry J. Kaiser Family Foundation; September 2010. http://www.kff.org/globalhealth/upload/8099.pdf. Accessed January 25, 2012.

8. Walsh L, Subbarao I, Gebbie K, et al. Core competencies for disaster medicine and public health. Disaster Med Public Health Prep. 2012;6(1): 44-52.

9. Office of the Assistant Secretary for Preparedness and Response, US Department of Health and Human Services. Biennial Implementation Plan for The National Health Security Strategy of the United States of America. Draft. Washington, DC: US Department of Health and Human Services; July 19, 2010. http://www.phe.gov/Preparedness/planning/authority/nhss /comments/Documents/nhssbip-draft-100719.pdf. Accessed January 30, 2012.

10. Association of Schools of Public Health. Global Health Competency Model. Final Version 1.1; October 31, 2011. http://www.asph.org/userfiles/Narrative \&GraphicGHCompsVersion1.1FINAL.pdf. Accessed January 30, 2012.

11. Establishing Common Competencies and Leadership Frameworks London. United Kingdom: Consortium of British Humanitarian Agencies (CBHA); 2010. http://www.thecbha.org/media/website/file/CBHA _Competency_Frameworks.pdf. Accessed January 29, 2012.

12. Redwood-Campbell L, Pakes B, Rouleau K, et al. Developing a curriculum framework for global health in family medicine: emerging principles, competencies, and educational approaches. BMC Med Educ. 2011;11: 46 http://www.biomedcentral.com/1472-6920/11/46. Accessed January 26, 2012.

13. Johnson K, Idzerda L, Baras R, et al. Common competencies for humanitarian providers. In: Proceedings of the Humanitarian Network Conference; November 3, 2011; Cambridge, Massachusetts: Harvard Humanitarian Initiative, Harvard University.

14. Public Health Preparedness and Response Core Competency Model. Final Model Version. 1.0. Centers for Disease Control and Prevention and the Association of Schools of Public Health; December 17, 2010. http: //www.asph.org/userfiles/PreparednessCompetencyModelWorkforce -Version1.0.pdf. Accessed January 24, 2012.

15. Network on Humanitarian Assistance International Association of Universities (NOHA) Professional Profiles and Competencies. http://www .nohanet.org/noha-master-programme/professional-profiles-and -competencies-.html. Accessed January 29, 2012.

16. Osler W. Aequanimitas, With Other Addresses to Medical Students, Nurses and Practitioners of Medicine. 3rd ed. New York, NY: McGraw-Hill Book Co; 1906:117. 